\title{
SIMULAÇÕES DO CLIMA DO HOLOCENO MÉDIO NA AMÉRICA DO SUL COM O MODELO DE CIRCULAÇÃO GERAL DA ATMOSFERA DO CPTEC.
}

\author{
MARIA LUCIENE DIAS DE MELO, JOSÉ ANTONIO MARENGO
}

\author{
Centro de Previsão de Tempo e Estudos Climáticos / \\ Instituto Nacional de Pesquisas Espaciais - CPTEC/INPE \\ Rodovia Presidente Dutra - 40 km, 12630-000 Cachoeira Paulista - São Paulo, Brazil.
}

Recebido Dezembro 2006 - Aceito Outubro 2007

\begin{abstract}
RESUMO
Neste trabalho são analisados os resultados de um conjunto de simulações que permite avaliar as variações climáticas no Holoceno Médio (HM) com relação ao clima atual na América do Sul (AS). Utiliza-se o MCGA do CPTEC com resolução T062 e 28 níveis na vertical (T062L28). Realizaram-se as simulações climáticas a partir da modificação dos parâmetros orbitais e da concentração de $\mathrm{CO} 2$ para valores típicos do HM. Os resultados foram comparados com simulações do PMIP e com os indícios paleoclimáticos na América do Sul, para avaliar a resposta do MCGA à variação dos parâmetros climáticos característicos do HM e avaliar diferenças do clima no presente e HM. Observou-se um comportamento mais úmido no nordeste da AS no HM. Na região central, sul e sudeste do continente o HM foi marcado por uma redução da precipitação. Quanto à temperatura verificou-se um sinal de resfriamento no HM que concorda com as evidencias paleoclimáticas observacionais. Observou-se um aumento da intensidade do fluxo médio do vento em $850 \mathrm{hPa}$, sobre o continente, no HM, devido diminuição na variação sazonal da insolação no Hemisfério Sul, que leva a menores gradientes de temperatura. Também se verificou a intensificação da circulação da alta subtropical do Atlântico Sul e enfraquecimento da circulação de norte a leste dos Andes durante todas as estações do ano. Esse enfraquecimento tem impacto significativo no transporte de umidade da bacia Amazônica para a bacia do Prata, e consequentemente sobre a formação da ZCAS.
\end{abstract}

Palavras chave: Holoceno Médio, América do Sul, MCGA CPTEC, paleoclima

\begin{abstract}
CLIMATE SIMULATIONS OF THE MID-HOLOCENE IN THE SOUTH AMERICA AS PRODUCED BY THE CPTEC ATMOSPHERIC GENERAL CIRCULATION MODEL

An ensemble of climate simulations with the CPTEC T062L28 AGCM is performed in order to obtain the present and Mid-Holocene (MH) climate in South America. The climatological characteristics simulated by the model are compared with PMIP models and paleoclimate records, and emphasis is given to the Southern Hemisphere and South America (SA). The orbital parameter and the CO2 concentration are changed for typical MH values. In general, the model simulations indicate a wetter Northeast. In the central region, south and southeast of the continent, the MH climate was marked by reduced precipitation in comparison with the present model climate. A cooling signal is observed in the $\mathrm{MH}$ according to the paleoclimatic evidences. A increase of the intensity of the $850 \mathrm{hPa}$ flow over the continent is produced by the model in the MH climate in comparison with the present model climate. The South Atlantic subtropical high intensity is increased and less intense climatological northerly flow east of the Andes during all seasons. This weakening of the northerly flow has a significant impact on the moisture transport from the Amazon to the La Plata basin, and consequently over the SACZ.
\end{abstract}

Key words: Mid Holocene, South America, CPTEC AGCM, paleoclimate 


\section{INTRODUÇÃO}

Os registros ou indicadores paleoclimáticos fornecem uma visão "observacional" de muito longo prazo do clima, de sua variabilidade natural e das mudanças induzidas por fatores externos ou antrópicos. Os indicadores paleoclimáticos são úteis para detectar mudanças em regimes climáticos no passado e para entender como é que o sistema climático funcionava no passado em comparação com o regime atual. Os registros paleoclimáticos também permitem validar as reconstruções de clima do passado, realizadas a partir de modelos climáticos.

Modelos climáticos podem simular realisticamente os impactos das variações dos parâmetros orbitais na simulação do clima do Holoceno Médio (período de 6.000 anos atrás, que no decorrer do texto será chamado de HM) que foi caracterizado por uma mudança climática natural, devido às variações nos parâmetros orbitais e menor concentração de $\mathrm{CO}_{2}$.

As evidencias observacionais sugerem que mudanças significativas da forçante climática durante o Holoceno induziram alterações significativas no clima em relação à temperatura, chuva, nível médio do mar, intensidade dos sistemas de monções e do El Niño Oscilação Sul ou ENSO (IPCC, 2001). Indicadores climáticos com alta resolução temporal sugerem que no Holoceno, o El Niño e talvez outros modos de variabilidade interanual foram impactados e reajustados pelas mudanças climáticas de grande escala, geradas pela variação nos parâmetros orbitais. Modelos climáticos têm sido usados para simular episódios de clima marcantes, como por exemplo, o clima durante o último máximo glacial ou LGM (Ganopolski, et al., 1998), ou da evolução do clima durante eventos de mudanças climáticas abruptas (Manabe e Stouffer, 1997) para ajudar a entender os mecanismos de mudança do clima no passado. Os modelos de circulação geral representam à única forma de poder testar hipóteses, como a teoria de Milankovich, que sugere que as glaciações iniciaram-se devido a mudanças nos ciclos orbitais, as quais causaram uma redução da radiação solar durante o verão do Hemisfério Norte (Khodri et al., 2001). Os modelos também permitem estabelecer uma associação entre causa e efeito no clima do passado, assim como ajudam a preencher o vácuo de informações entre a escala regional e global do paleoclima, pois os indicadores paleoclimáticos são muito esparsos no tempo e no espaço. Um entendimento quantitativo destes mecanismos é a melhor forma de aprender sobre clima do passado ou do futuro, já que não existem análogos diretos do futuro no passado.

Existem evidências do "feedback" climático positivo na resposta observada às mudanças dos parâmetros orbitais. Comparações entre modelos e entre modelos e dados paleoclimáticos observados têm sido feitas pelo "Paleoclimate Modelling Intercomparison Project" (PMIP) (Jossaume e
Taylor, 1995). Ainda que simulações para o HM, derivadas de modelos climáticos atmosféricos produzam uma intensificação nos sistemas de monções, em resposta as mudanças nos parâmetros orbitais de 6.000 anos atrás, os modelos subestimam a precipitação (Joussaume et al., 1999).

O clima do HM representa um bom teste para avaliar o desempenho dos modelos de circulação geral atmosférica (MCGA), principalmente, por: (a) ser um período paleoclimático relativamente recente, marcado por uma mudança climática natural, para o qual as características médias climáticas são similares as do clima presente; (b) existirem indicadores paleoclimáticos referentes a esse período, os quais permitem a validação dos resultados do modelo; e (c) permitir a comparação dos resultados dessa integração com simulações-padrão do $\mathrm{HM}$, realizadas pelos vários centros climáticos mundiais, usando modelos globais climáticos no PMIP I e II (Braconnot et al, 2000). No PMIP todos os modelos que participaram do projeto tiveram os parâmetros orbitais alterados, a concentração de dióxido de carbono $\left(\mathrm{CO}_{2}\right)$ foi reduzida para $280 \mathrm{ppm}$, as condições de superfície e as temperaturas da superfície do mar (TSM) são consideradas iguais aos valores do presente, dada a falta de dados nessa época, e também devido TSM do HM ser similar às condições do presente, ou seja, uma atmosfera préindustrial (Valdes, 2000). Ruddiman e Mix (1993) e Morley e Dworetzky (1993), a partir da análise de sedimentos oceânicos, verificaram que as mudanças na TSM, no período do HM, foram muito pequenas. Sendo assim, apenas a forçante radiativa deve ter a maior contribuição para a mudança do clima do HM com relação ao clima atual.

Diversas características do clima geradas por experimentos, para o $\mathrm{HM} \mathrm{e} \mathrm{o} \mathrm{LMG,} \mathrm{foram} \mathrm{captadas} \mathrm{por} \mathrm{todos}$ os modelos, incluindo o resfriamento global no LMG e a expansão da monção de verão do Hemisfério Norte, no HM. No entanto, as diferenças na magnitude das respostas dos modelos são grandes.

No Hemisfério Sul, reconstruções de temperatura na Antártica, durante o Holoceno mostram aquecimento entre 11.000 e 9.000 anos, seguidos de um esfriamento gradativo no Holoceno tardio (Masson et al., 2000). Este período relativamente mais quente não pode ser explicado apenas pelas mudanças na insolação, mas talvez pela reorganização na grande escala do transporte latitudinal de calor pelos oceanos e atmosfera. A utilização dos MCGA torna possível simular os impactos das mudanças antrópicas na composição atmosférica e do uso da terra (IPCC, 2001), bem como o impacto de mudanças naturais, por exemplo, a mudança dos parâmetros orbitais que é bastante significativa em comparação, por exemplo, com a mudança da forçante radiativa induzida pela variação da concentração dos gases de efeito estufa entre o HM e o presente. No Hemisfério sul, entre dezembro e fevereiro a insolação média 
teve um decréscimo de 19,0 W. $\mathrm{m}^{-2}$, durante o Holoceno Médio em relação ao presente, o equivalente a uma diminuição de $4,8 \%$ da insolação dos dias atuais (Vettoretti, et al. 1998). Quanto à forçante antrópica, mudanças na concentração de $\mathrm{CO}_{2}$, que têm um grande impacto sobre a energética global, segundo Zhao et al. (2005), a diferença da concentração de dióxido de carbono entre o Holoceno Médio e o clima presente corresponde a uma forçante média adicional de $-0,88 \mathrm{~W} \cdot \mathrm{m}^{-2}$, já o IPCC (2007) sugere que a mudança na forçante radiativa devido ao $\mathrm{CO}_{2}$ é de $0,4 \mathrm{~W} \cdot \mathrm{m}^{-2}$.

A radiação solar disponível no topo da atmosfera, no período do HM foi significativamente diferente da quantidade de radiação nos dias de hoje, isso devido à mudança dos parâmetros orbitais. Há 6.000 anos, durante o verão do Hemisfério Norte (aproximadamente agosto) a Terra estava mais próxima do sol (periélio) do que no presente e o ciclo sazonal da insolação foi modificado. Portanto, no HM o máximo de insolação nos trópicos ocorria em agosto e o mínimo em fevereiro. No Hemisfério Norte esta mudança orbital intensificou o ciclo sazonal da insolação (Liu, et al., 2004). A mudança na insolação não é exatamente simétrica com relação ao equador, devido à inclinação do eixo rotacional da Terra $\left(24,1^{\circ}\right.$ há 6.000 anos e $23,4^{\circ}$ no presente) e a excentricidade que também foi diferente durante o HM (CP - 0,016724 e HM - 0,018682).

Diversos estudos utilizando o MCGA do CPTEC têm sido realizados para testar a habilidade do modelo em simular as características atmosféricas e sua variabilidade em escalas interanuais e decadais para o clima do presente (Cavalcanti et al. 2002; Marengo et al. 2003 e Marengo 2005). No entanto, o modelo do CPTEC ainda não foi utilizado para simulações paleoclimáticas ou cenário futuros.

Vários estudos foram realizados, com o intuito de simular o clima do HM, principalmente pelo PMIP I e II. No entanto, a maioria desses estudos dá ênfase aos efeitos no Hemisfério Norte e reportaram importantes mudanças no sistema de monção da Ásia e África. Por exemplo: Jossaume et al. (1999) analisaram o clima de 6.000 a partir da simulação de 18 modelos e confirmaram o aumento da amplitude do ciclo sazonal da temperatura no Hemisfério Norte e a redução no Hemisfério Sul. Todos os modelos reproduziram o aumento da precipitação de monção da Ásia e África, marcado por uma expansão, para norte, da zona de precipitação mais intensa. No entanto, todos os modelos subestimaram a intensidade da monção, no norte da África; Gagan et al. (1998) observaram que o oceano tropical apresentou-se mais aquecido (anomalia de TSM $>+1^{\circ}$ C) durante o HM e mais frio (ATSM $<-2^{\circ} \mathrm{C}$ ) durante o LGM. Ao analisar outros indicadores, eles concluíram que o clima foi mais quente entre $7.000-4.000$ anos atrás.

Estudos paleoambientais com indicadores paleoclimáticos têm sido realizados para diversas regiões da América do Sul e fornecem uma representação aproximada do clima no passado. Esses estudos revelaram um comportamento mais seco durante o HM sobre a região amazônica (Turcq et al., 1998; Behling et al., 2000; Turcq et al., 2002) e sul e sudeste brasileiro (Behling, 2001; Turcq et al., 2002). Além disso, Mayle et al. (2000) e Haug et al. (2001), analisando o Norte e Nordeste da América do Sul, verificaram o deslocamento da ZCIT para sul durante o HM em comparação com a posição atual, confirmando as simulações de Silva Dias et al. (2002) que, utilizando o modelo global acoplado oceano-atmosfera do Institut Pierre et Simon Laplace da Universidade de Paris (IPSL), verificaram que a região nordeste do Brasil encontrava-se mais úmida e mais fria (principalmente no verão) e, em média, a estação seca era mais curta, durante o HM. Keefer et al (2003), a partir da análise de dados paleoclimáticos da costa sul do Peru, verificaram que eventos severos de El Niño ocorreram durante todo o Plestioceno e em duas ou três divisões do Holoceno, com freqüências significativamente diferentes. No entanto, o período de maior intensidade do El Nino, no Holoceno, foi entre 11.000 e 9.000 anos atrás. Durante o HM, só foram registrados quatro eventos severos de El Nino (Keefer et al., 2003), pois os registros paleoclimáticos sugerem baixa intensidade e freqüência da ocorrência de El Nino no HM. Essas condições também foram verificadas por Fontugne et al. (1999) que analisaram recordes paleoclimáticos da Quebrada de los Burros, no Departamento de Tacna no sul do Peru. No entanto, Thompson (1995) verificou a partir da análise de núcleos de gelo, que a região do Peru encontrava-se mais quente, que os dias atuais entre 8.200 e 5.200 anos atrás. Sifeddine et al. (2003) analisando dados lacustres, na região nordeste do Brasil $\left(2,96^{\circ} \mathrm{S}\right.$ e $\left.43,41^{\circ} \mathrm{W}\right)$ verificaram uma queda no nível do lago, entre 11.000 e 4.500 anos atrás, o que foi interpretado como um período mais seco, comparando-se aos dias atuais. Esse resultado foi confirmado por Ledru et al. (2002) em dados de pólen.

O HM é conhecido como um período de mudanças particularmente significativas do clima (Steig, 1999). Dados da Antártica e Groenlândia mostraram uma diminuição na temperatura atmosférica, durante o HM (Steig, 1997). As TSM do Atlântico Norte subiram e no Pacífico Equatorial e oceano Ártico houve resfriamento da superfície (Gagan et al, 1998) criando um dipolo entre o Hemisfério Norte e Sul (Pessenda et al, 2004).

A ênfase dada ao HM é devido às condições marcantes desse período, na qual o maior fator "forçante" é bem conhecido (mudança dos parâmetros orbitais) e também, devido à relativa abundância de indicadores paleoclimáticos existentes nesse período. É necessário que se avance na compreensão de como os modelos climáticos respondem a grandes mudanças nas forçantes climáticas, quer sejam de origem natural ou antrópica. Assim, um estudo do comportamento e da capacidade do modelo 
em simular as características de grande escala do HM, viabilizará o entendimento dos possíveis mecanismos responsáveis pela mudança do clima no passado, o que certamente ajudaria muito na compreensão das possíveis mudanças no clima do futuro.

Com base no exposto, o objetivo geral deste trabalho foi analisar, a partir do modelo de circulação geral atmosférica do CPTEC com resolução T062 e 28 níveis na vertical (T062L28), as variações climáticas durante o Holoceno Médio (6.000 anos atrás), com enfoque sobre a América do Sul. Essa análise foi feita a partir da modificação dos parâmetros orbitais e concentração de $\mathrm{CO}_{2}$ para valores típicos do HM. As simulações foram comparadas com as realizadas pelo PMIP e com indicadores paleoclimáticos da América do Sul, com intuito de analisar os vários modelos juntos em relação ao clima do HM, e também validar as características climáticas simuladas neste período.

\section{MATERIAL E METODOLOGIA}

Foram realizados dois conjuntos de simulações de 40 anos (controle e HMS1) Tabela 1. Ambos experimentos foram realizados com a TSM climatológica do AMIP (1956 a 2003) como condição de contorno, e as condições iniciais foram retiradas do estado da atmosfera estimado pelas análises operacionais do National Centers for Environmental Prediction/ National Center for Atmospheric Research (NCEP/NCAR). O uso desse conjunto de dados é permitido devido o período do HM não ser caracterizado por uma glaciação ou superaquecimento e sim, por ser um período marcado por características médias climáticas similares as do clima atual (Seppã et al., 2005) uma atmosfera pré-industrial (Valdes, 2000). Os três primeiros anos de integração foram desprezados devido ao ajuste da umidade do solo e das condições iniciais ("spinup" do ciclo hidrológico). A concentração de $\mathrm{CO}_{2}$ e os parâmetros orbitais, calculados segundo Berger (1978), correspondentes ao período do HM são descritos nas Tabelas (1 e 2), respectivamente. A concentração de $\mathrm{CO}_{2}$, para o HM foi de 280 ppm, valor referente ao do período pré-industrial e o mesmo utilizado nas simulações - padrão do PMIP. Esse valor foi verificado por Petit, et al. (1999), que analisaram uma amostra de gelo de Vostok, que datava 420.000 anos atrás.

Tabela 1 - Resumo dos experimentos realizados

\begin{tabular}{|c|c|c|c|c|}
\hline Experimento & Parâmetros Orbitais & TSM & Concentração de $\mathrm{CO}_{2}$ & Membros do ensemble \\
\hline CP & Atual & AMII & $345 \mathrm{ppm}$ & cinco \\
\hline HMS1 & Berger (1978) & AMIP & $280 \mathrm{ppm}$ & cinco \\
\hline
\end{tabular}

Tabela 2 - Parâmetros orbitais para o Clima Presente e o HM (6.000 anos atrás)

\begin{tabular}{|c|c|c|}
\hline Parâmetros Orbitais & Clima Presente & Holoceno Médio \\
\hline Obliqüidade & 23,440 & 24,105 \\
\hline Excentricidade & 0,016724 & 0,018682 \\
\hline Precessão dos Equinócios & 102,04 & 0,87 \\
\hline
\end{tabular}




\subsection{Modelo de Circulação Geral Atmosférica do CPTEC}

Neste trabalho, utilizou-se o MCGA do CPTEC/ INPE. Esta é a primeira vez que o MCGA do CPTEC/INPE é integrado e testado em experimentos de simulação de paleoclima. O MCGA possui uma resolução T062L28. A resolução horizontal é aproximadamente a mesma de $200 \mathrm{~km}$ no equador. O MCGA utiliza um módulo de superfície, o Simplified Simple Biosphere Model (SSiB), que considera a influência da vegetação de uma forma mais sofisticada (Xue et al., 1991). As parametrizações dos processos físicos utilizadas no modelo são: radiação de onda curta, segundo Lacis e Hansen (1974), modificada por Ramaswamy e Freidenreinch (1992); radiação de onda longa por Harshvardhan et al. (1987); convecção profunda do tipo Kuo (1965); convecção rasa, segundo Tiedtke (1983) e Cavalcanti, et al. (2002).

$\mathrm{O}$ valor atual da concentração de $\mathrm{CO}_{2}$ atual utilizada no modelo é de $345 \mathrm{ppm}$. No entanto, esse valor de $\mathrm{CO}_{2}$ é fixo e menor que a concentração de dióxido de carbono dos dias atuais que é da ordem de $370 \mathrm{ppm}$. Contudo, a simulação do clima presente foi mantida no valor de $345 \mathrm{ppm}$, para efeitos de comparações com outras simulações já existentes, para o clima presente, realizadas pelo PMIP (Braconnot et al, 2000).

De posse dos conjuntos de simulações (CP e HMS1) foram analisados e comparados os ciclos anuais da radiação de onda curta (ROC), médias sazonais da temperatura, precipitação, pressão ao nível médio do mar, radiação de onda longa e circulação atmosférica em baixos níveis, com o intuito de verificar os padrões de grande escala associados à circulação atmosférica durante o HM e no clima presente. Todas as análises foram feitas com ênfase sobre a América do Sul. Em seguida, foram discutidas as diferenças climáticas entre os períodos e as simulações comparadas com resultados de modelos do PMIP (Jossaume e Taylor, 1995; Valdes, 2000, dentre outros) a fim de observar como diferentes modelos reproduzem as mudanças climáticas devidas às variações no ciclo sazonal da insolação, ocasionadas pela mudança dos parâmetros orbitais e a sinergia entre a concentração de $\mathrm{CO}_{2}$ e variação desses parâmetros. E por fim, para validar o MCGA do CPTEC compararamse os resultados com estudos paleoambientais (Tabela 3).

Tabela 3 - Indicadores paleoclimáticos

\begin{tabular}{|c|c|c|}
\hline Tipo de dado & Localidade & Referência \\
\hline Pólen fossilizado & Sudoeste do Pacífico & Sandweiss et al., (1996) \\
\hline $\begin{array}{l}\text { Sedimento datando } 12000 \\
\text { anos }\end{array}$ & $\begin{array}{l}\text { Laguna de Palcacocha en el sur del } \\
\text { Ecuador }\end{array}$ & Moy et al. (2002) \\
\hline $\begin{array}{l}\text { Fragmentos de carvão e } \\
\text { sedimentos lacustres }\end{array}$ & Serra sul dos Carajás & Turcq et al (1998) \\
\hline Pólen fossilizado & Laguna Loma Linda in eastern Colombia & Behling et al. (2000) \\
\hline $\begin{array}{l}\text { Sedimentos lacustres, } \\
\text { árvores e madeira }\end{array}$ & $\begin{array}{l}\text { Lago Serra do Norte de Carajás, Lago } \\
\text { Caracarana (Boa Vista), Lago Preta de } \\
\text { Baixo e Dom Helvecio (Minas Gerais) e } \\
\text { Lago Feia (Brasília) }\end{array}$ & Turcq et al. (2002) \\
\hline Sedimentos lacustres & Barreirinhas (Nordeste do Brasil) & Sifeddine et al. (2003) \\
\hline $\begin{array}{l}\text { Isótopos de Carbono e } \\
\text { Matéria orgânica do Solo }\end{array}$ & Sul da Amazônia e Rondônia & Pessenda (1998c) \\
\hline $\begin{array}{l}\text { Fragmentos de carvão e } \\
\text { Isótopos de Carbono }\end{array}$ & Sudeste do Brasil & Pessenda (2004a) \\
\hline Solos & $\begin{array}{l}\text { Barreirinhas (Estado do } \text { Maranhão } \\
\text { Nordeste do Brasil) }\end{array}$ & Pessenda et al. (2005) \\
\hline
\end{tabular}




\section{RESULTADOS E DISCUSSÕES}

A Figura 1 mostra a diferença do ciclo anual da quantidade de radiação de ondas curtas (ROC) que chega ao topo da atmosfera, entre o HM e o presente. Verifica-se que durante o HM a quantidade de radiação no topo da atmosfera foi diferente dos dias de hoje, devido à mudança dos parâmetros orbitais. A Terra esteve mais próxima do sol no inverno do Hemisfério Sul durante o HM, exatamente o oposto do presente (Silva Dias et al, 2002). Como resultado dessa mudança da insolação, mais radiação de onda curta chegava entre março e julho e menos entre outubro e fevereiro, entre $0^{\circ}$ e $30^{\circ} \mathrm{S}$, desintensificando o ciclo sazonal da insolação nos trópicos do Hemisfério Sul, concordando com os resultados de Valdes (2000) e intensificando o ciclo sazonal da insolação no Hemisfério Norte (Liu et al., 2004). Verifica-se ainda, no campo da diferença entre a radiação que chega no topo da atmosfera no HM e no clima presente, outro máximo de insolação durante o HM, no período da primavera entre $40^{\circ} \mathrm{S}$ e $90^{\circ} \mathrm{S}$, que concorda com os resultados de Braconnot et al. (2000). No Hemisfério Norte, entre junho e agosto (JJA), a insolação média aumentou $20,7 \mathrm{Wm}^{-2}$, cerca de $4,7 \%$ do valor atual. No Hemisfério Sul, entre dezembro e fevereiro (DJF), a insolação média teve um decréscimo de $19,0 \mathrm{Wm}^{-2}$, durante o HM, o equivalente a uma diminuição de $-4,8 \%$ da insolação do presente (Vettoretti, et al. 1998).

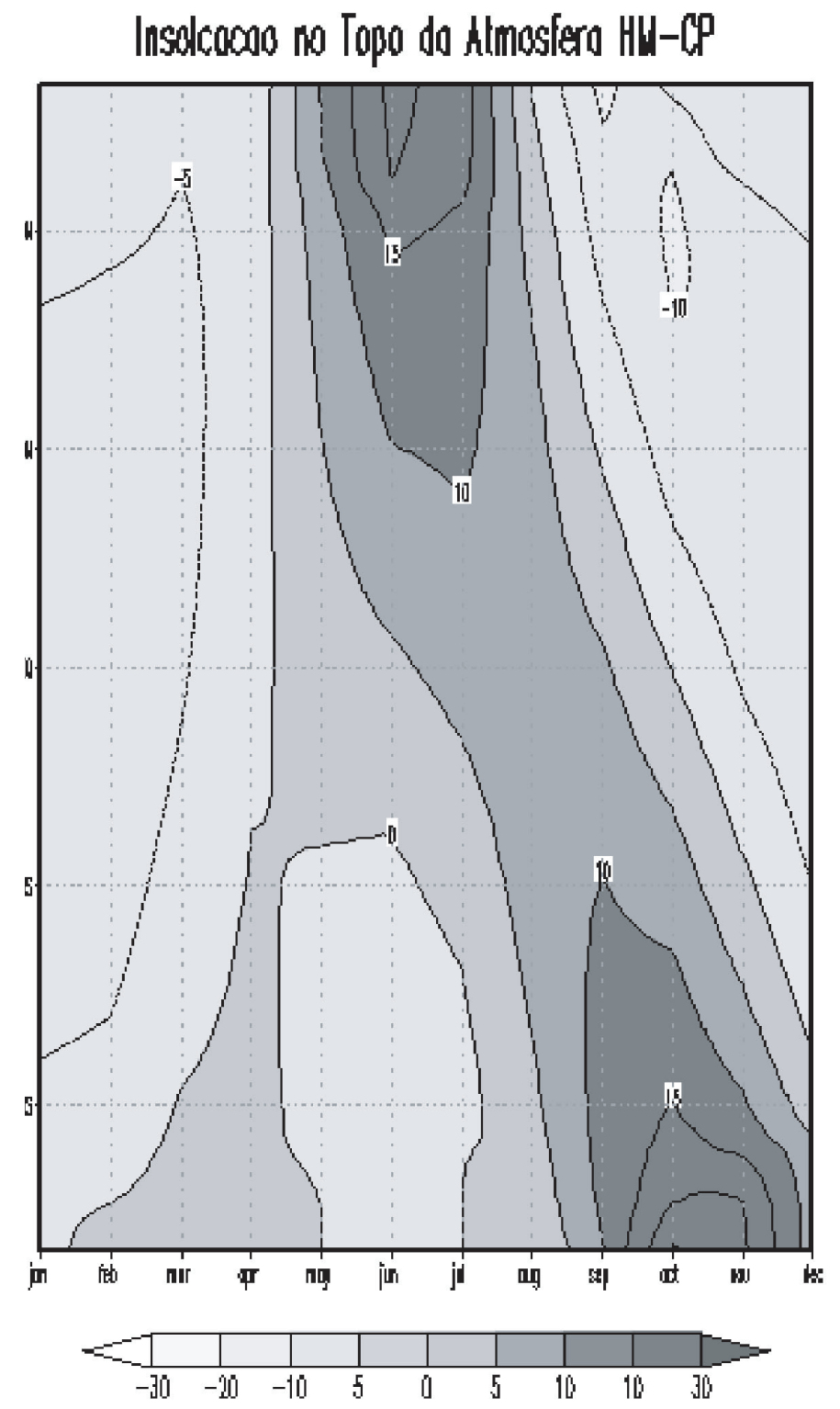

Figura 1 - Diferença da ROC que chega ao topo da atmosfera (w.m²), entre o período do HM e os dias de hoje (HM-CP). 
A Figura 2 ilustra o campo da precipitação média sazonal durante o HM e o campo da diferença da precipitação média sazonal entre o HM e os dias atuais (HMS1-CP), para as quatro estações do ano. Essa figura sugere que, de maneira geral, o Nordeste brasileiro encontrava-se mais úmido (em torno de $10 \%$ ) há 6.000 anos (experimento HMS1), concordando com os campos do fluxo de calor latente (não mostrado) que durante todo o ano aumentou aproximadamente $20 \%$, principalmente na faixa leste do Nordeste brasileiro. Verifica-se ainda, que a região Amazônica encontrava-se ligeiramente mais seca (em torno de $10 \%$ ) no experimento HMS1, comparada ao presente, concordando com os dados paleoclimáticos (Turcq et al., 1998; Behling et al, Turcq et al. 2002), A região sul e centro oeste do Brasil estava mais seca durante o HMS1. Essa redução da precipitação pode ser devida à desintensificação do escoamento de norte (Figura 3), a leste dos Andes, durante o HM, que reduz o transporte da umidade da bacia Amazônica (Figura 4) para a região nordeste e sudeste do Brasil. Isto influencia a formação e posição da Zona de Convergência do Atlântico Sul (ZCAS), causando uma redução da precipitação na posição atual do ZCAS.

Essas características podem ser reforçadas a partir do campo de Radiação de Onda Longa Emergente-ROLE (não mostrado) que sugere mínimo de radiação nas regiões de máxima precipitação que é o caso da região da Zona de Convergência Intertropical, Zona de Convergência do Atlântico Sul e região Amazônica. O campo da diferença de radiação de onda longa, entre os experimentos HMS1 e CP, sugere como um todo um aumento da ROLE para toda América do Sul. No entanto, esse aumento da ROLE pode estar relacionado apenas com o aumento da nebulosidade e não necessariamente com a precipitação. Entretanto, observa-se que para as maiores diferenças de precipitação verifica-se o sinal da ROLE mais intenso, que é o caso da região Amazônica, onde ocorreu um aumento da radiação para a redução da chuva, e redução da ROLE para aumento de precipitação na região nordeste da América do Sul.
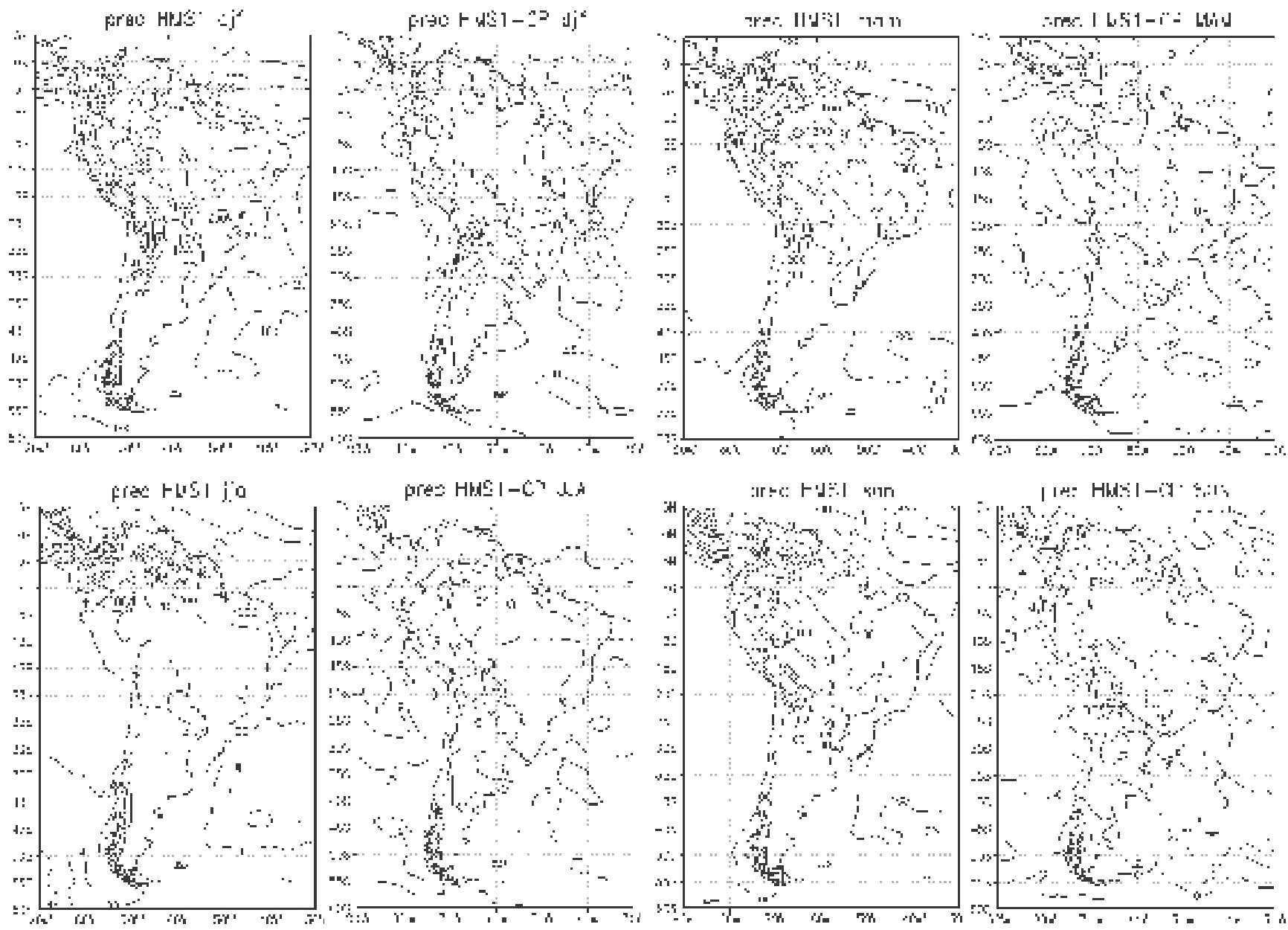

Figura 2 - (lado direito) Precipitação média sazonal ( $\mathrm{mm}$ ) e (lado esquerdo) Diferença da precipitação média sazonal, entre o período do HM e os dias de hoje. 
A partir da análise da Figura 3, verifica-se um aumento da intensidade do fluxo médio do vento em $850 \mathrm{hPa}$, sobre o continente, durante o HM, especialmente na costa leste da América do Sul, devido a intensificação da alta subtropical do Atlântico Sul e sua proximidade do continente. Este padrão durante o verão no HM é similar ao observado no outono e inverno no clima presente. Diante disso, algumas mudanças significativas podem ser observadas como: (a) intensificação da circulação da alta subtropical do Atlântico Sul (ASAS); (b) diminuição do escoamento de norte a leste dos Andes (o que sugere uma possível influencia na intensidade da circulação do jato de baixos níveis ou "Low Level Jet"- LLJ) durante todas as estações, no período do $\mathrm{HM}$, exceto ao sul de $20^{\circ} \mathrm{S}$, onde se verifica ligeira intensificação do fluxo na direção noroeste/ sudeste, devido ASAS, entretanto, esse fluxo contem menos umidade que o proveniente da região Amazônica. Nos dias atuais, o padrão do outono e inverno mostra um fluxo do LLJ vindo da ASAS que está mais perto do continente neste período do ano. Mesmo que o fluxo do LLJ seja mais forte, o conteúdo de umidade é mais baixo do que o fluxo de umidade das massas de ar transportadas pelos ventos alísios durante o verão que são de origem amazônica e que também são transportados pelos LLJ (Marengo et al., 2004), e a ZCAS é mais fraca ou ausente nestas estações, no clima atual. Fazendo uma analogia com o HM, a circulação de verão neste período, mostra uma redução do fluxo da região Amazônica devido ao enfraquecimento dos ventos alísios de nordeste, contribuindo para uma redução da precipitação nessa região.

A alta subtropical do Atlântico Sul ficou mais intensa e próxima do continente, durante o verão no $\mathrm{HM}$, assim o LLJ a leste dos Andes, tornou-se mais forte, ao sul de $20^{\circ} \mathrm{S}$, intensificando o transporte de umidade para a região da ZCAS (seção sul da ZCAS, principalmente). Porém, essa umidade não é proveniente da região Amazônica e sim do Atlântico Sul. Esse padrão de verão no HM é similar ao padrão de outono e inverno no CP. Já no inverno austral no HM houve uma desintensificação da ASAS, semelhante ao ocorrido no clima presente. Essa menor intensidade facilitaria a penetração de frentes frias, as quais conseguiram entrar até mais ao norte da América do Sul, produzindo maior resfriamento e possíveis chuvas na região central do Brasil e sul da Amazônica, no HM; (c) ligeira intensificação dos alísios de sudeste e enfraquecimento dos ventos alísios de nordeste que pode explicar o deslocamento mais ao norte da ZCIT e diminuição da convergência dos ventos sobre a região Amazônica que, por sua vez, pode elucidar a redução da precipitação nessa região durante o HM.

Comparando as simulações HMS1 e CP, observa-se que o posicionamento da Alta da Bolívia (AB) e cavado do Nordeste são similares em ambos experimentos (não mostrado), no entanto com intensidades ligeiramente distintas. Verificou- se o cavado do Nordeste mais intenso e a AB ligeiramente enfraquecida durante o verão austral, no experimento HMS1. Isso sugere que a circulação de altos e baixos níveis da América do Sul, onde nesta última observa-se uma mudança no sinal da componente do vento em $850 \mathrm{hPa}$ entre as estações de verão e inverno, descreve um sistema monçônico durante o verão austral, mesmo que ligeiramente mais fraco comparado ao presente. Esse enfraquecimento reflete na desintensificação da ZCAS e no enfraquecimento da $\mathrm{AB}$, com uma redução da precipitação sobre a América do Sul. Isso com exceção à região do nordeste do Brasil, onde há um ligeiro aumento da precipitação, associado ao recuo da precipitação de monção da região central da Amazônia para a costa leste do Nordeste brasileiro (Liu et al, 2004).

A Figura 4 apresenta diferença do fluxo de umidade médio sazonal integrado da superfície até $300 \mathrm{hPa}$, entre o período do $\mathrm{HM}$ e os dias de hoje (HMS1-CP), nas quatro estações do ano. A principal característica do campo da diferença do fluxo de umidade é que o transporte de umidade oceano-continente é aumentado durante o período do HM, principalmente na costa Atlântica, sul da América do Sul e no Nordeste Brasileiro. Isso também foi constatado por Kohfeld e Harrison (2000) que a partir da análise de dados de lagos, verificaram condições mais úmidas que o presente, em quase todo o globo, com exceção do interior da América do Norte e oeste da Europa. Observa-se que o transporte de vapor do oceano Atlântico para a região Amazônica diminuiu o que explica a redução da precipitação nessa região. $\mathrm{O}$ transporte de umidade da região Amazônica para a região central e sudeste do Brasil também foi reduzido durante o HM, o que pode ter influenciado no posicionamento e intensidade da ZCAS há 6.000 anos.

A Figura 5 ilustra o campo da temperatura média sazonal durante o HM e a diferença da temperatura entre o HMS1 e o clima atual (HMS1-CP), para as quatro estações do ano. O campo da diferença entre a temperatura média sazonal do HMS1 e o clima atual, sugere que a região nordeste do Brasil encontrava-se ligeiramente mais fria (anomalias negativas de até $0,2^{\circ} \mathrm{C}$ ), com exceção da estação de inverno, para qual se observa anomalias positivas de no máximo $0,2^{\circ} \mathrm{C}$, concordando com Valdes (2000). Sinal contrário foi verificado sobre as regiões sul, sudeste e central brasileiras, que durante o HM estiveram ligeiramente mais aquecidas (anomalias positivas superiores a $0,2^{\circ} \mathrm{C}$ ), com exceção do inverno onde se verifica anomalias negativas de temperatura (acima de $0,3^{\circ} \mathrm{C}$ ). A região Amazônica apresenta um sinal de aquecimento para o $\mathrm{HM}$, principalmente no lado leste e oeste, já a região central da Amazônia sugere resfriamento neste período.

De forma geral, a Figura 5 sugere que a América do Sul esteve mais fria (anomalias negativas superiores a $0,3^{\circ} \mathrm{C}$ ), no experimento HMS1 concordando com Steig (1997) que 

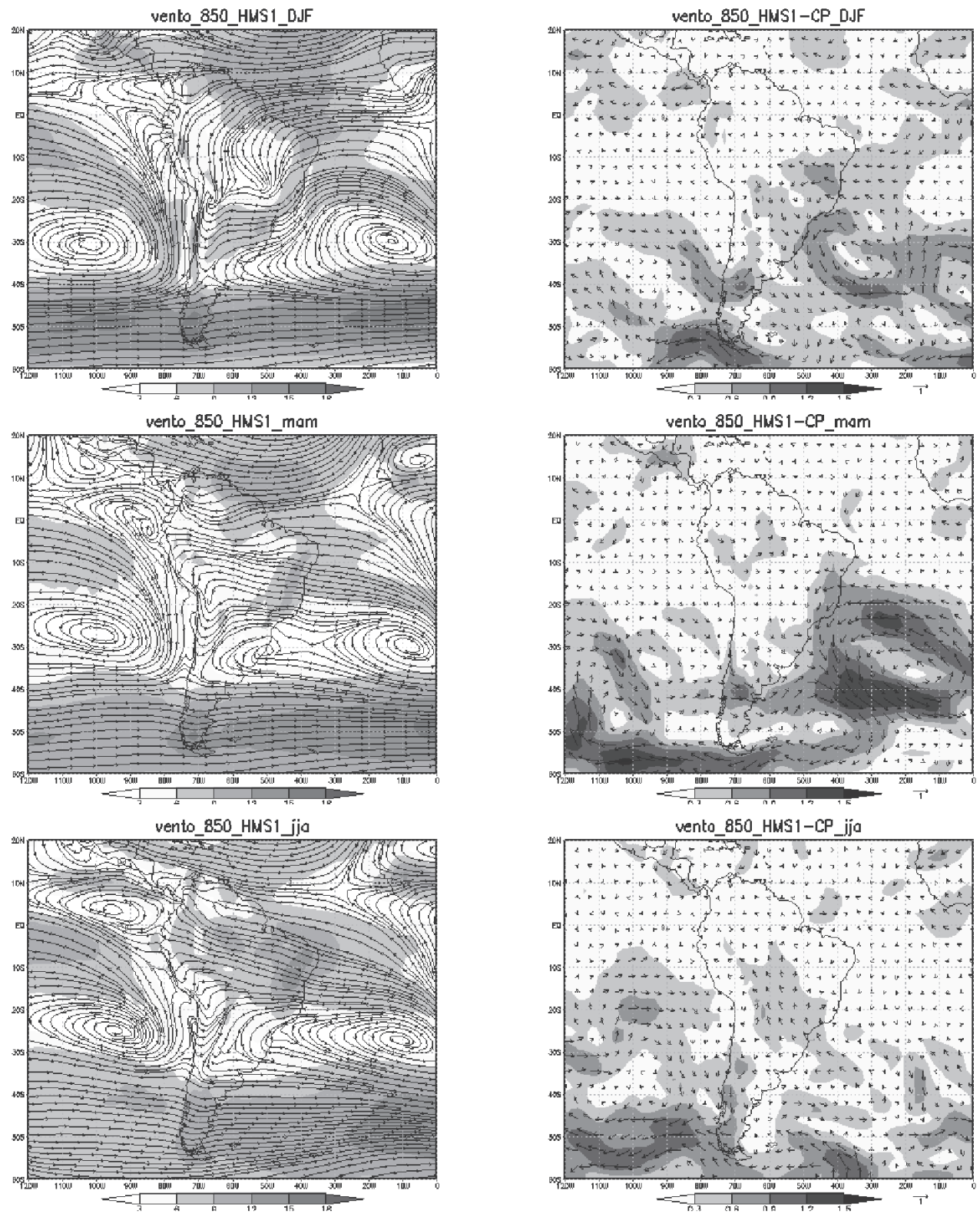

vento 850 HUS1 son
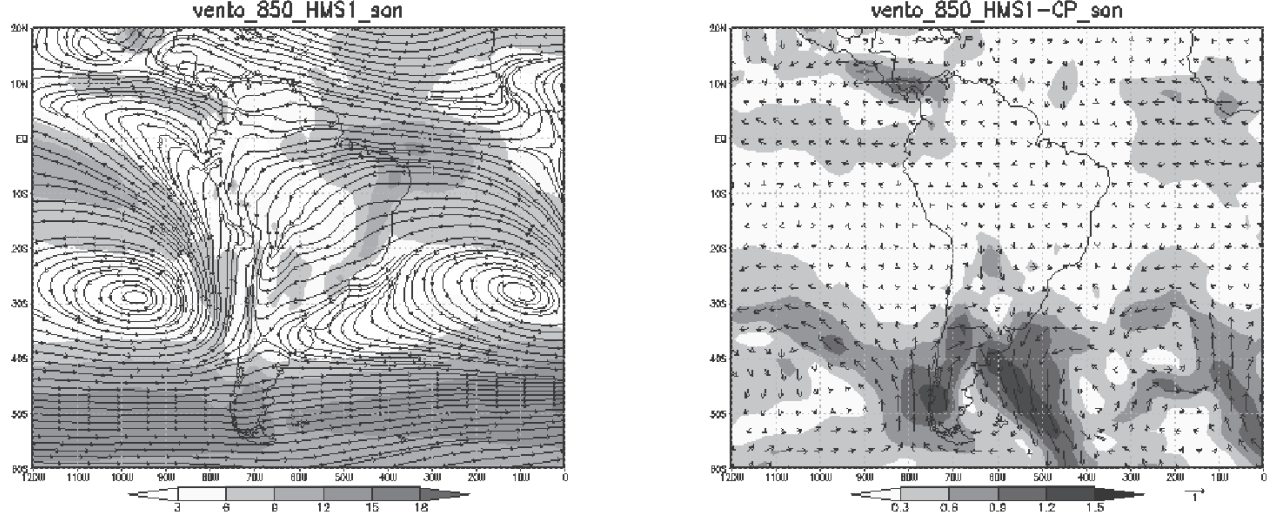

Figura 3 - Diferença vento médio sazonal no nível de $850 \mathrm{hPa}\left(\mathrm{m} \cdot \mathrm{s}^{-1}\right)$, entre o período do HM e os dias de hoje (HM1-CP). a) DJF; b) MAM; c) JJA e d) SON. 
verificou uma redução da temperatura durante o HM. Um pequeno gradiente térmico é verificado sobre a América do Sul, anomalias negativas na região nordeste e Amazônica e positivas nas regiões central, sudeste e sul do Brasil. Esse gradiente se inverte durante o inverno.

Em resumo comportamento mais chuvoso sobre a região nordeste da América do Sul, durante todo ano no período do HM (experimento HMS1), foi verificado no entanto, a região amazônica, no período do HM foi marcada por uma redução das precipitações o que concorda com as evidências paleoambientais (Turcq et al., 1998; Behling et al., 2000; Turcq et al., 2002).
Quanto à temperatura, na superfície verificou-se um sinal de resfriamento (anomalia negativa de $3^{\circ} \mathrm{C}$ ) para o período de 6.000 anos atrás, durante todo o ano, sobre a América do Sul, exceto para a região amazônica e sul do Brasil, onde os campos sugerem um sinal de aquecimento durante quase todo o ano, concordando com Valdes (2000).

A Figura 6 ilustra a média sazonal da pressão ao nível médio do mar para todo o globo, para o experimento HMS1 e a diferença entre os experimentos HMS1 e CP, para as quatro estações do ano. Verifica-se que para o experimento HMS1 a distribuição do campo da pressão é muito similar a dos dias
Diff Fluxo de Umidade DJF HMS1-CP

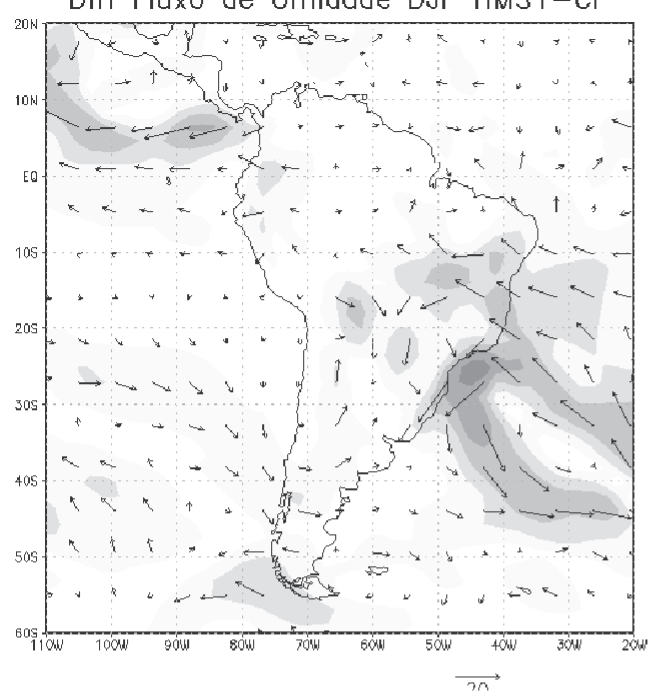

Diff Fluxo de Umidode JJA HMS1-CP

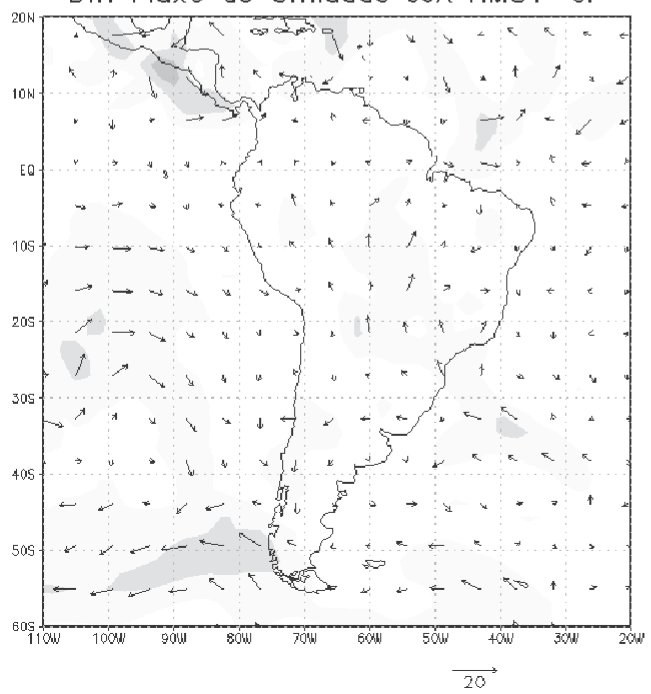

Diff Fluxo de Umidade MAM HMS1-CP

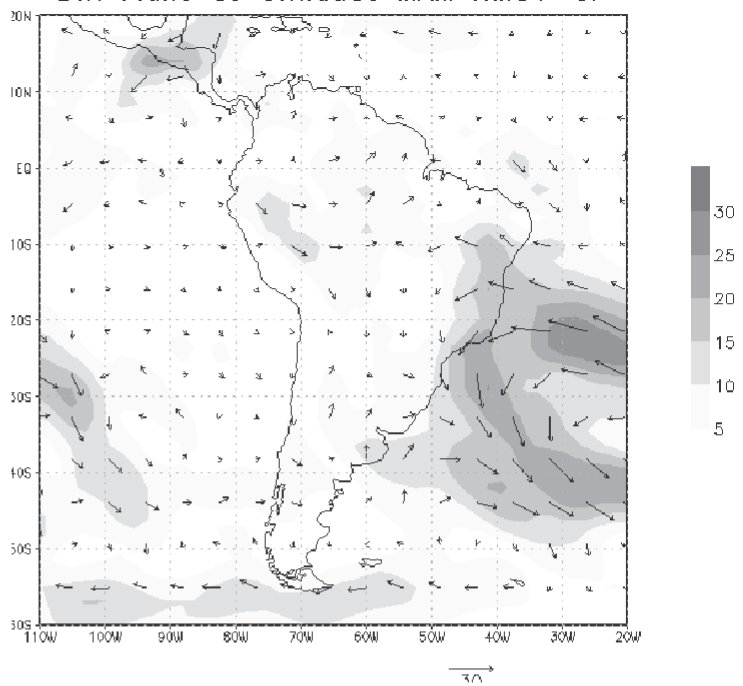

Diff Fluxo de Umidade SON HMS1-CP

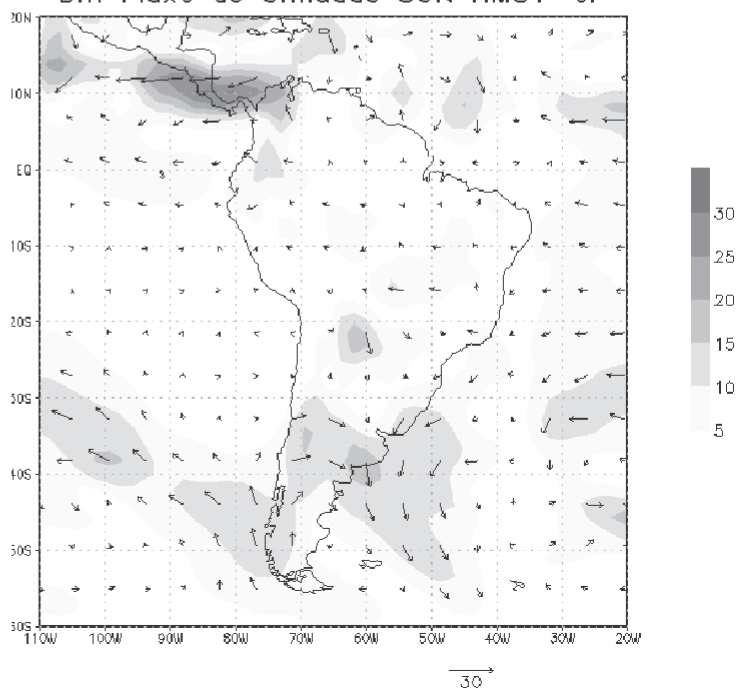

Figura 4 - Diferença do fluxo de umidade médio sazonal $\left(\mathrm{Kg}_{\mathrm{m}} \mathrm{m}^{-2} \cdot \mathrm{s}^{-1}\right)$, integrado da superfície até 300hPa, entre o período do HM e os dias de hoje (HM1-CP). a) DJF; b) MAM; c) JJA e d) SON. 
de hoje, apresentando as regiões de baixa pressão próximo dos pólos, altas pressões nos subtrópicos e o cinturão de baixa pressão na faixa equatorial, observadas atualmente em ambos os hemisférios. No campo da diferença, entre os experimentos HMS1 e CP, observa-se que as diferenças são sutis. Em geral, o campo
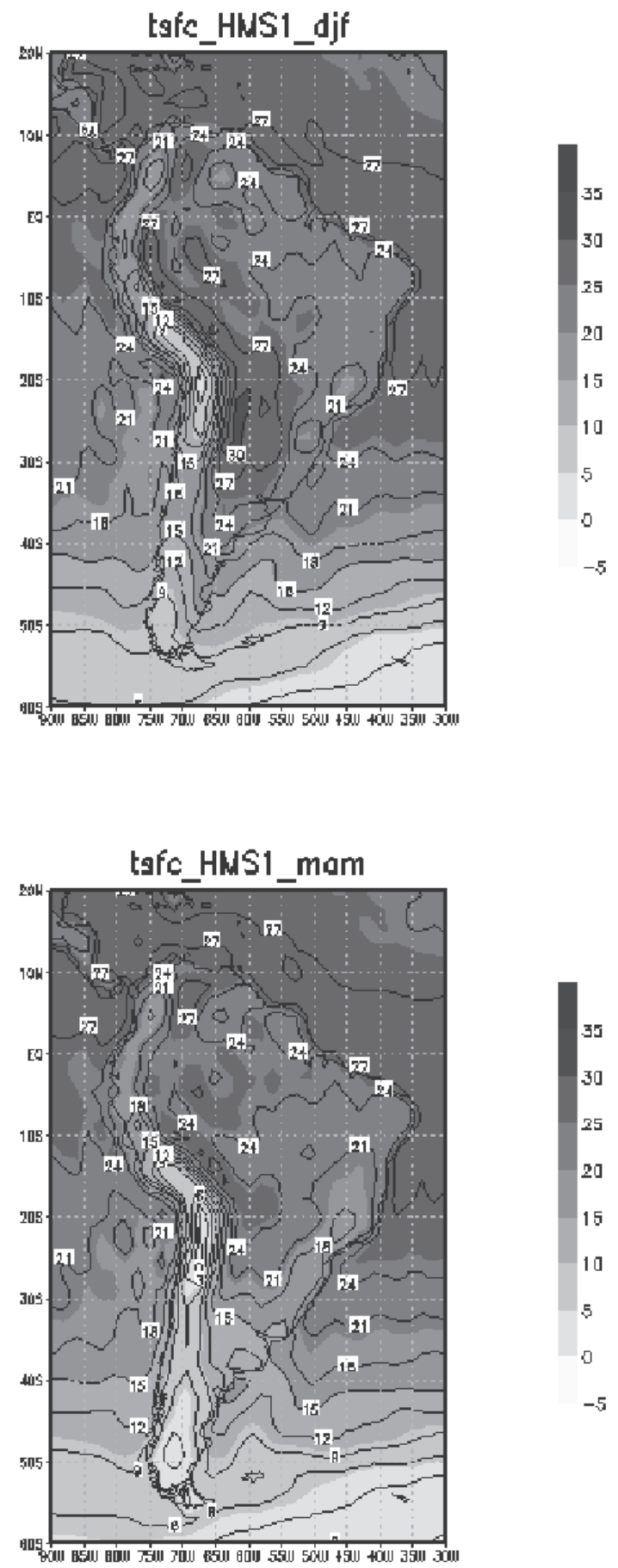

da diferença sugere uma desintensificação da Alta Subtropical do Atlântico e desintensificação da alta do Pacífico Sul (ASAS e ASPS ), durante quase todo ano, com exceção da estação da primavera austral, onde se observa uma intensificação (ASPS e ASAS), além da intensificação da Baixa Térmica do Chaco.
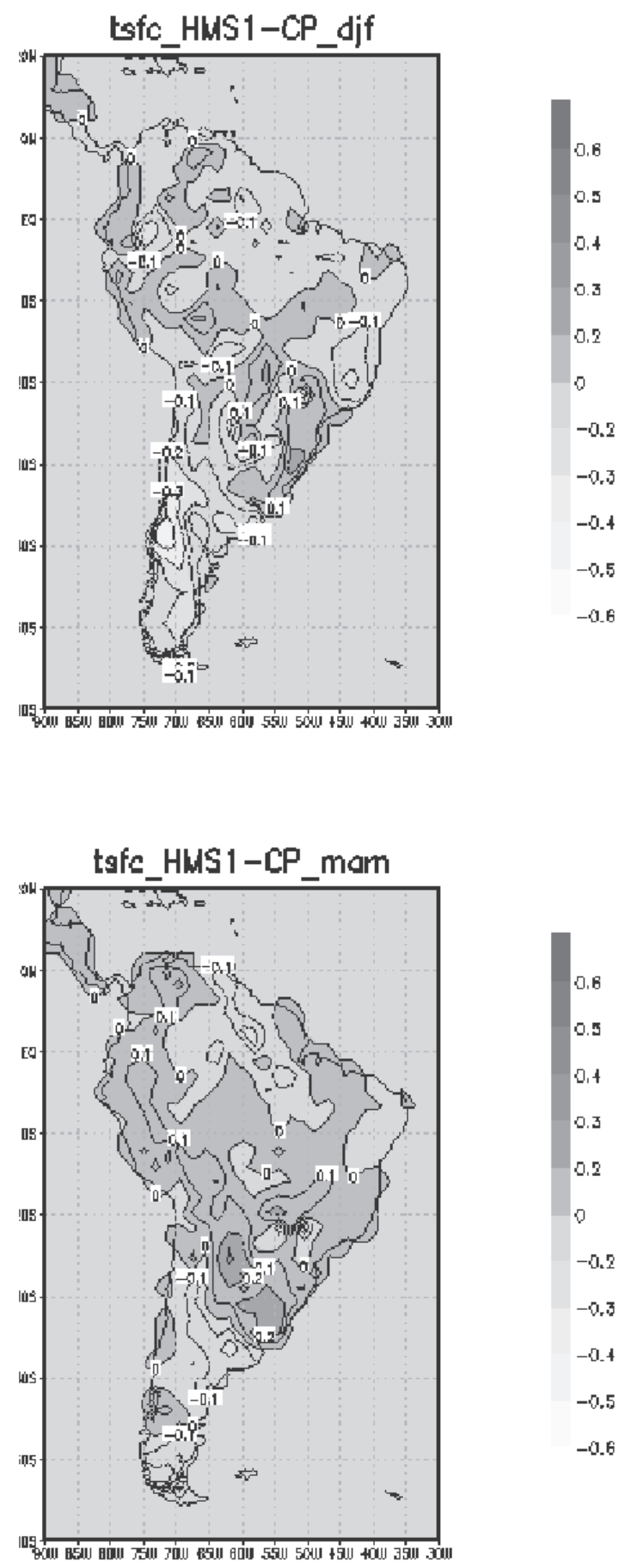

Figura 5 - (lado esquerdo) Temperatura média sazonal na superfície $\left({ }^{\circ} \mathrm{C}\right)$ no período do $\mathrm{HM}$ e (lado direito) Diferença da temperatura média sazonal, entre o período do HM e os dias de hoje. c) JJA e d) SON. 


\section{CONCLUSÕES}

As mudanças nos parâmetros orbitais da Terra no período do HM fizeram com que o ciclo sazonal da insolação fosse modificado em ambos os hemisférios. Confrontando os resultados das simulações do MCGA do CPTEC T062L28 com indicadores paleoclimáticos e simulações de paleoclimas
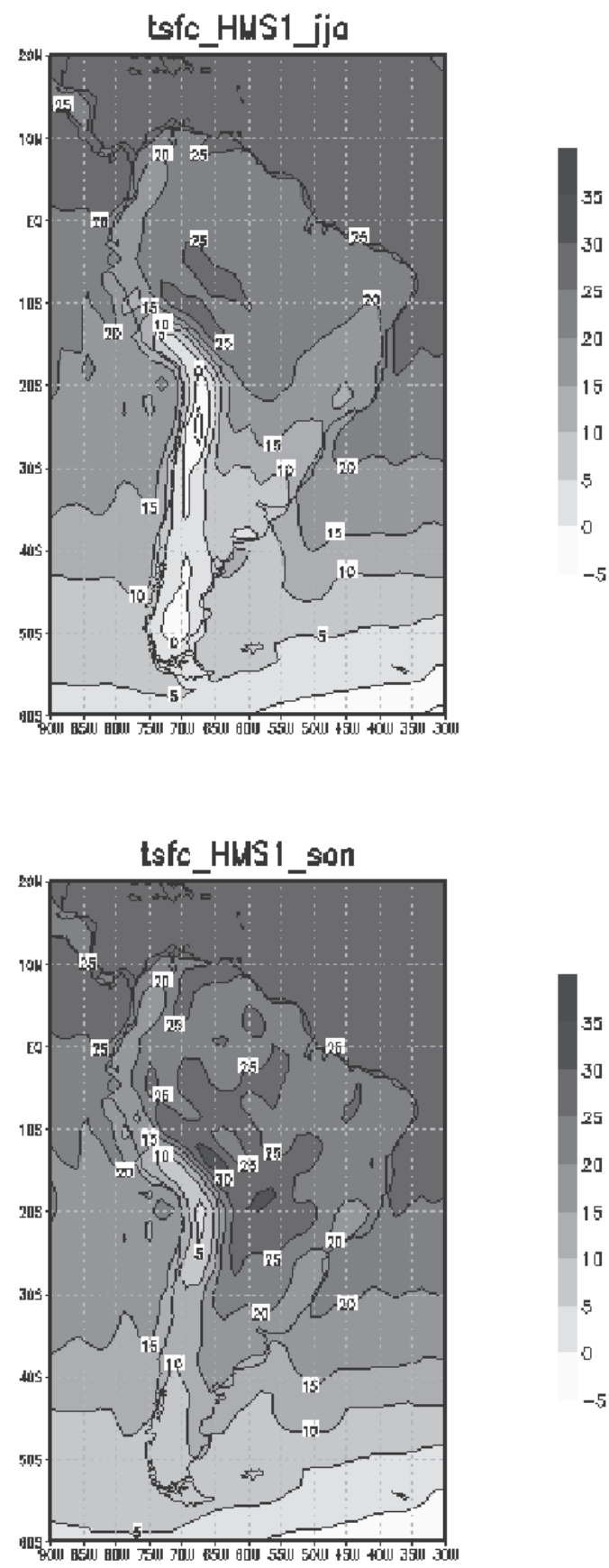

resultantes dos modelos do PMIP verificam-se que, em geral, o modelo conseguiu simular os padrões climáticos de grande escala para o período do HM. As simulações do clima no Holoceno sugerem que o Nordeste brasileiro encontrava-se mais frio e úmido e a região sul sudeste e centro oeste esteve mais seca para aquele período, concordando com os resultados encontrados por Valdes (2000).
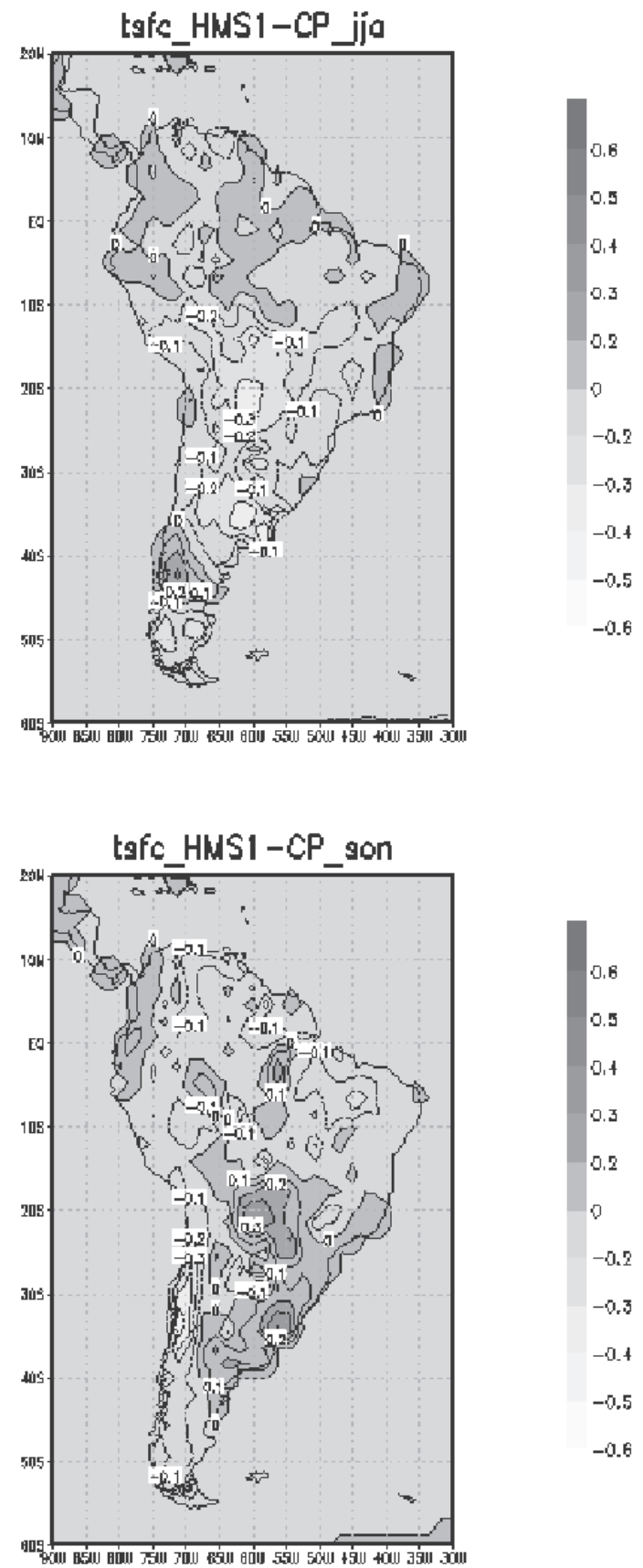

Figura 5 - (Continuação) (lado esquerdo) Temperatura média sazonal na superfície $\left({ }^{\circ} \mathrm{C}\right)$ no período do HM e (lado direito) Diferença da temperatura média sazonal, entre o período do HM e os dias de hoje. a) DJF; b) MAM. 
Nos campos de vento médio sazonal no nível de $850 \mathrm{hPa}$, foi detectada a intensificação da intensidade do fluxo médio em $850 \mathrm{hPa}$ sobre o continente durante o HM, especialmente na costa leste da América do Sul. Diante disso, algumas mudanças significativas podem ser observadas: (a) a intensificação da circulação da alta subtropical do Atlântico Sul; (b) a diminuição do escoamento a leste dos Andes e intensificação, no verão, ao sul de $20^{\circ} \mathrm{S}$, (c) a redução no transporte da umidade da bacia Amazônica para a região central e sudeste, o que influencia a formação e intensidade das ZCAS; (e) desintensificação dos
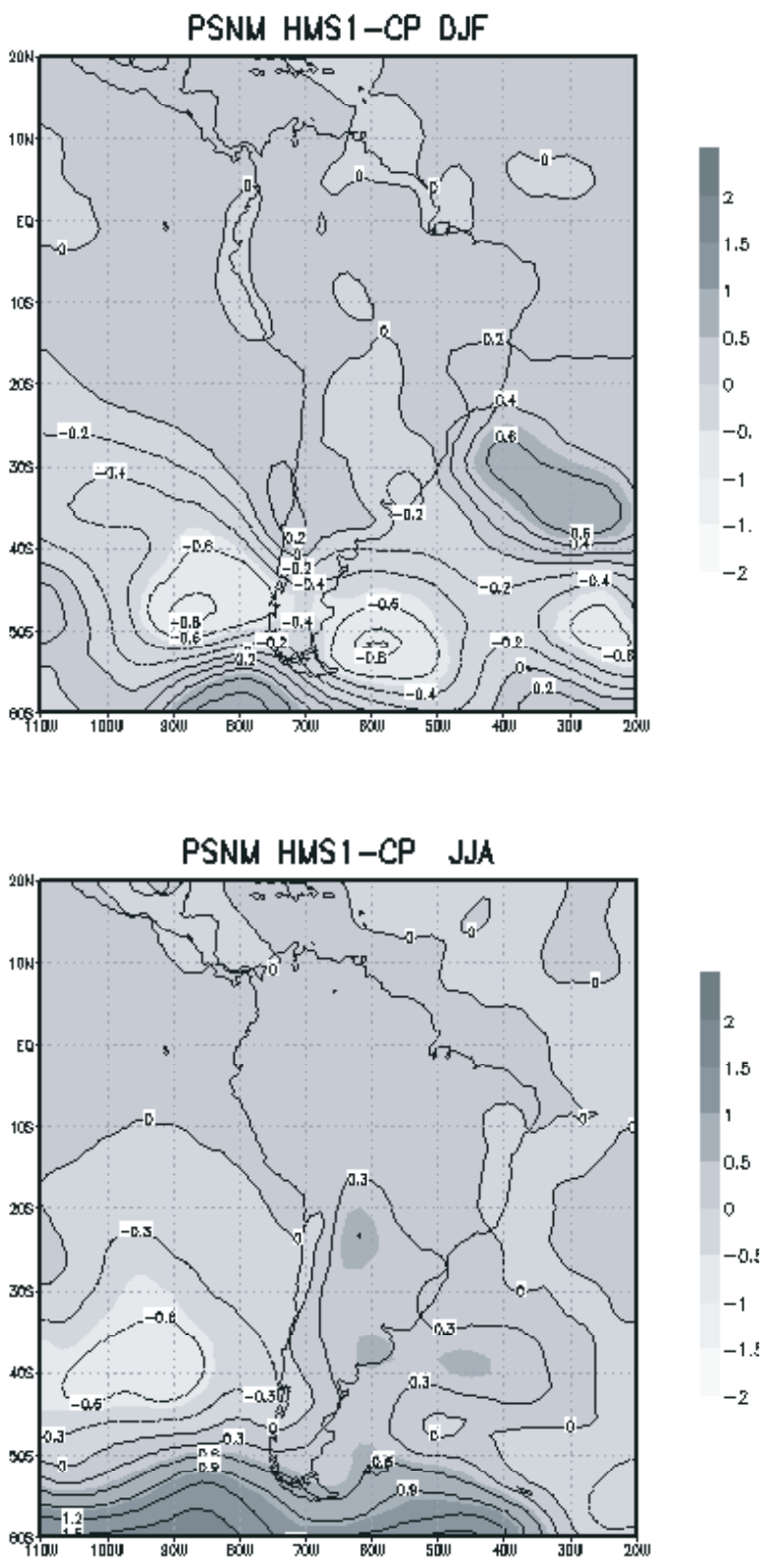

ventos alísios de nordeste o que pode explicar o deslocamento mais ao norte da ZCIT, e (f) diminuição da convergência dos ventos sobre a região Amazônica, o que pode explicar a redução da precipitação nessa região durante o HM.

Também foi observada uma mudança de sinal na componente do vento entre as estações de verão e inverno, sobre a região amazônica, desintensificação da Alta da Bolívia e intensificação no cavado do nordeste o que sugere que a circulação tipo monção da América do Sul, também existiu no período do HM, com características similares ao presente,
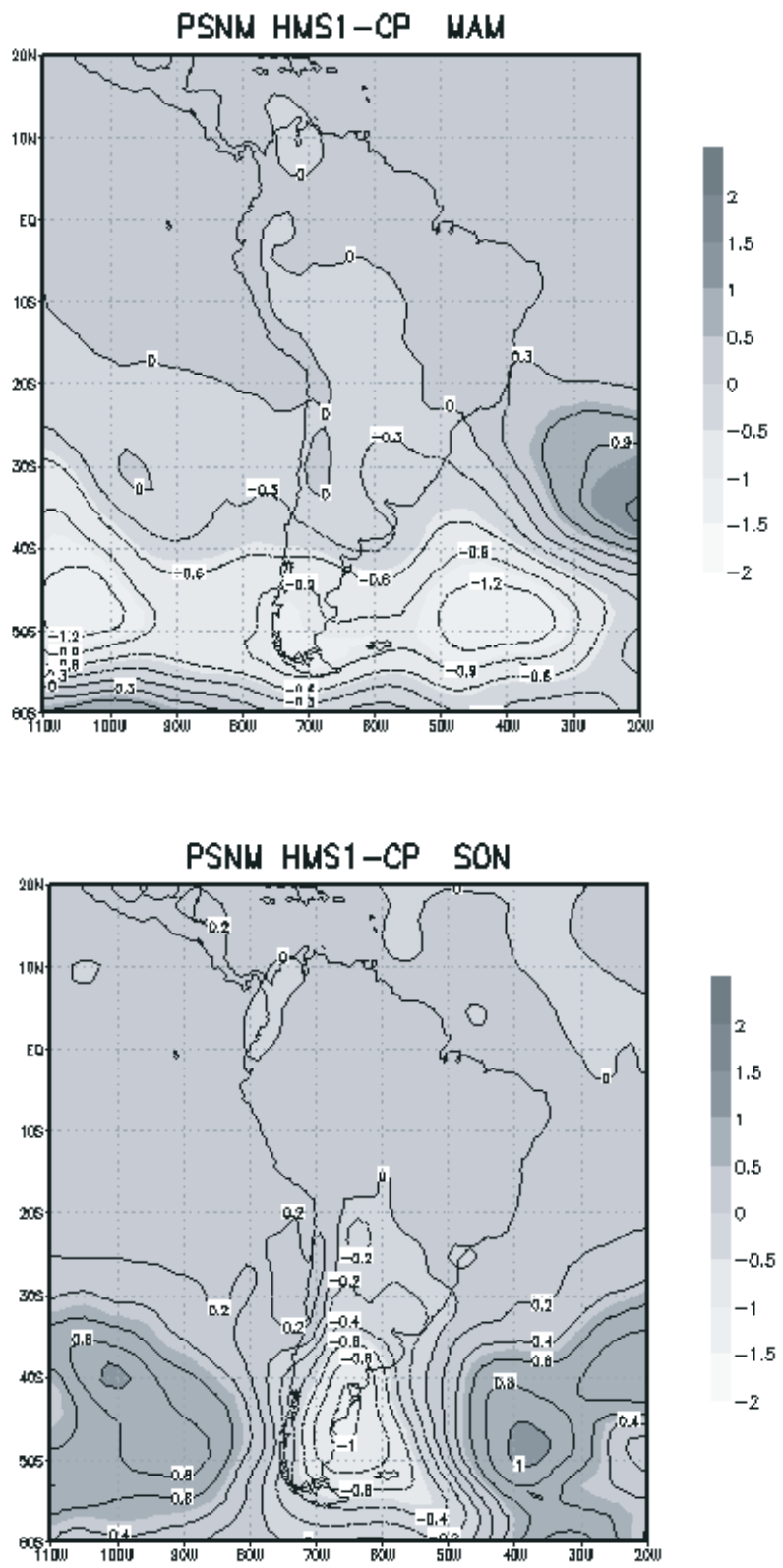

Figura 6 -Diferença da pressão média sazonal ao nível médio do mar, entre o período do HM e os dias de hoje (HM1-CP). a) DJF; b) MAM; c) JJA e d) SON. 
no entanto, ligeiramente mais fraca. Os resultados, de maneira geral concordam com as simulações padrões do PMIP e com as evidências paleoambientais.

No que se refere à temperatura na superfície, observou-se que, em geral, o modelo do CPTEC simulou um resfriamento durante o período do $\mathrm{HM}$ que pode ser devido à redução da concentração de $\mathrm{CO}_{2}$ e redução do ciclo sazonal da insolação, que concorda com evidências paleoclimáticas de Steig (1997). Entretanto, o resfriamento produzido pela redução da concentração de $\mathrm{CO}_{2}$ deve ser significativamente inferior ao induzido pela redução da forçante radiativa (IPCC, 2007)

Os resultados sugerem que o MCGA do CPTEC captou de maneira geral os padrões de grande escala da atmosfera para um período geológico recente, marcado por uma mudança climática natural, como foi o Holoceno Medio.

\section{REFERÊNCIAS BIBLIOGRÁFICAS}

BEHLING, H.; NEGRET, A. J.; HOOGHIEMSTRA, H. Holocene Amazon rainforest-savanna dynamics and climatic implications: high-resolution pollen record from Laguna Loma Linda in eastern Colombia. Journal of Quaternary Science, v. 15 , n. 7, p. 687-695. 2000

BEHLING, H. South and southeast Brazilian grasslands during Late Quaternary times: a synthesis. Palaeogeography, Palaeoclimatology, Palaeoecology, v. 2710, p. 1-9. 2001.

BEHLING, H.; PILLAR, V. D.; ORLÓCI, L.; BAUERMANN, S. G. Late Quaternary Araucaria forest, grassland (Campos), fire and climate dynamics, studied by high-resolution pollen, charcoal and multivariate analysis of the Cambará. do Sul core in southern Brazil. Palaeogeography, Palaeoclimatology, Palaeoecology, v.203, p. 277-297. 2004.

BERGER, A. L. Notes and Correspondence: Long-Term Variations of Daily Insolation and Quaternary Climatic Changes. Journal of Atmospheric Science. v. 35, p. $2362-$ 2367. 1978.

BRACONNOT, P.; JOUSSAUME, S.; DE NOBLET, N.; RAMSTEIN G. Mid-holocene and Last Glacial Maximum African monsoon changes as simulated within the Paleoclimate Modelling Intercomparison Project. Global and Planetary Change 26: (1-3) p. 51-66. 2000.

CAVALCANTI, I. F. A. et al. Global Climatological Features in a Simulation Using the CPTEC-COLA AGCM. Journal of Climate. 15: (21) p. 2965-2988. 2002.

FONTUGNE, M.; USSELMANN, P.; LAVALLÈE, D.; JULIEN, M.; HATTĖ, C. El Nino Variability in the Coastal Desert of Southern Peru during the Mid-Holocene. Quaternary Research. V. 52, n. 2, p. 171-179. 1999.

GAGAN, M.K. et al. Temperature and surface-ocean water balance of the mid-Holocene tropical western Pacific. Science, v. 279, p. 1014--1017. 1998.

GANOPOLSKI, A. et al. Simulation of modern and glacial climates with a coupled global model of intermediate complexity. Nature, v. 391, p. 351-356, 1998.

HARSHVARDHAN, K. M.; BROMWICH, D. H.; CORSETT, T. G. A fast radiation parameterization for general circulation models. Journal Geophysical Research, v. 92, p.1009-1016. 1987.

HAUG, G. H. et al. Southward Migration of the Intertropical Convergence Zone Through the Holocene. Science, v. 293, p. 1304-1308, 2001.

INTERGOVERNMENTAL PANEL ON CLIMATE CHANGE IPCC. Climate Change 2001: the scientific basis IPCC WG I TAR. Cambridge: Cambridge Univ. Press. pp.881, 2001.

INTERGOVERNMENTAL PANEL ON CLIMATE CHANGE IPCC. Climate Change 2007: The Physical Scientific Basis IPCC AR4 WG I Cambridge: Cambridge Univ. Press. pp.498.

JOSSAUME, S.; TAYLOR, K. E. Status of the paleoclimate Modeling Intercomparison Project. In Proceedings of the First International AMIP Scientifc Conference, WCRP (World Climate Researche Programme) - 92. Moterey; p. 425 - 430. 1995.

JOUSSAUME, S. et al. Monsoon changes for 6000 years ago: Results of 18 simulations from the Paleoclimate Modeling Intercomparison Project (PMIP). Geophysical Research Letters, 26: (7), p. 859-862. 1999.

KEEFER, D. K; MOSELEY, M. E.; deFRANCE S.D. A 38000year record of floods and debris flows in the Ilo region of the Southern Peru and its relation to El Nino events and great earthquakes. Paleogeography, Paleoclimatology, Paleoecology. v.194, n.1, p. 41-77. 2003.

KHODRI M, et al. Simulating the Amplification of Orbital Forcing by Ocean Feedbacks in the Last Glaciation. Nature, 410 (6828): p. 570-574. 2001

KOHFELD, K.E. and HARRISON, S.P. How well can we simulate past climates? Evaluating the models using global palaeoenvironmental datasets. Quaternary Science Reviews, v. 19, p. 321- 346. 2000.

KUO, H.L. On formation and intensification of tropical cyclones through latente heat release by cumulus convection. Journal of the Atmospheric Sciences, v. 22, n. 1, p. 40-63, 1965.

LACIS, A. A.; HANSEN, J. E. A parameterization of the absorption of the solar radiation in the earth's atmosphere. Journal of the Atmospheric Sciences, 31, p. 118-133. 1974.

LEDRU, M.P., et al. A. Tropical climates in the game of two hemispheres revealed by abrupt climatic change. Geology 30, p. 275-78. 2002. 
LIU, Z; HARRISON, S.P.; KUTZBACH, J.; OTTO-BLIESNER, B. Global monsoons in the mid-Holocene and oceanic feedback. Climate Dynamics. p. 157-182. 2004.

MANABE, S; STOUFER, R. J. Coupled ocean-atmosphere model response to freshwater input: comparision to Younger Dryas event. Paleocenography, v. 12, p. 321-336. 1997.

MARENGO, J. A. et al. Assessment of regional seasonal rainfall predictability using the CPTEC-COLA atmospheric GCM. Climate Dynamics. 21, p. 459 - 475. 2003.

MARENGO, J. A., SAULO, C., NICOLINI, M. Climatology of the Low-Level Jet of the Andes as Derived from the NCEPNCAR Reanalyses: Characteristics and Temporal Variability. Journal of Climate. v. 17 (12), p. 2261-2279. 2004.

MARENGO, J. A. Characteristics and spatio-temporal variability of the Amazon river basin water budget. Climate Dynamics, v. 24, p. 11-22. 2005

MASSON V, et al. Holocene climate variability in Antarctica based on 11 ice-core isotopic records. Quaternary Research, 54 (3): p. 348-358. 2000.

MAYLE, F. E.; BURBRIDGE, R.; KILLEEN, T. J. MillenialScale Dynamics of Southern Amazonian Rain Forests. Science, v. 290, p. 2291--2294, 2000.

MORLEY, J. J.; DWORETZKY, B. A. Holocene temeprature patterns and the South Atlantic, Southern and Pacific oceans. Global Climates since the Last Glacial Maximun, H. E. Wright et al., Eds., University of Minnesota Press, p. 125-135. 1993.

PESSENDA, L.C.R. et al. Holocene fire and vegetation changes in southeastern Brazil as deduced from fossil charcoal and soil carbon isotopes. Quaternary International, v. 114, p. 35-43. 2004.

PETIT, J. R. et al. Climate and atmospheric history of the past 420,000 years from the Vostok ice core, Antartica. Nature, v. 399, p. 429-436, 1999.

RAMASWAMY, V; S. M. FREIDENREICH, 1992: A Study of Broadband Parameterizations of the Solar Radiative Interactions with Water Vapor and Water Drops. J.Geophys. Res., 97, 11487-11512.

RUDDIMAN, W. F.; MIX, A. C. The North and equatorial Atlantic at 9000 and 6000 years B.P. Global Climates since the Last Glacial Maximun, H. E. Wright et al., Eds., University of Minnesota Press, 94-124. 1993.
SEPPÃ, H.; HAMMARLUND, D.; ANTONSSON, K. Lowfrequency changes in temperature and effetive humidity during the Holocene in south-central Sweden: implications for atmospheric and oceanic forcings of climate. Climate Dynamics. 25, 285-297. 2005.

SIFEDDINE, A. et al. A 21000 cal years paleoclimatic record from Caco Lake, northern Brazil: evidence from sedimentary and pollen analyses. Palaeogeography, Palaeoclimatology, Palaeoecology 189, 25-34. 2003

STEIG, E.J. Mid-Holocene climate change. Science 286, 1485 87. 1999

STEIG, E.J. How well can we parameterize past accumulation rates in polar ice sheets? (1997) Annals of Glaciology, 25, pp. X66-422.

SILVA DIAS, P. L.; SILVA DIAS, M. A.; BRACONNOT, P.; TURC, B. Evaluation of Model Simulation of $6 \mathrm{k}$ and Present Climate in South America. In: Congresso Brasileiro de Meteorologia, 12., 2002.. Foz do Iguaçu. Anais. São Paulo: USP, 2002.

THOMPSON, E. et al. 1995. Late glacial stage and Holocene tropical ice core records from Huascaran, Peru. Science 269, 46-50.

TIEDTKE, M., 1983. The sensitivity of the time-mean largescale flow to cumulus convection in the ECMWF model. Pro. Workshop on convection in large-Scale Numerical Models, Reading, United Kingdom, ECMWF, 297-316.

TURCQ, B. et al.. Amazonia rainforest fires: A lacustre record of 7000 years. Ambio, v. 27, n. 2, 139-142, 1998.

TURCQ, B. et al. Accumulation of organic carbon in five Brazilian lakes during the Holocene. Sedimentary Geology, v. 148, 319-342, 2002.

VALDES, P. J. South American paleoclimate model simulations: how reliable are the models? Journal of Quaternary Science, v. 15, n. 4 , p. $357-368,2000$.

VETTORETTI, G.; PELTIER, W. R.; MCFARLANE, N. A. Simulations of Mid-Holocene Using an Atmospheric General Circulation Model. Journal of Climate, v. 11, n. 10, p. 2607-2627, 1998.

XUE, Y.; SELLERS, P. J.; KINTER, J. L.; SHUKLA, J. A Simplified Biosphere Model for global climate studies. Journal of Climate, 4, 345-364. 1991. 